\title{
Studi Penggunaan Limbah Styrofoam Pada Perkerasan Aspal Porus
}

\author{
Elsa Eka Putri ${ }^{1}$, Hermistanora ${ }^{2}$, Bayu Martanto Adji ${ }^{3}$ \\ Jurusan Teknik Sipil, Universitas Andalas, $1,2,3$ \\ email: elsaeka@eng.unand.ac.id ${ }^{1}$, hermistanora2015@gmail.com² ${ }^{2}$,bayu@eng.unand.ac.id ${ }^{3}$ \\ DOI: http://dx.doi.org/10.31869/rtj.v3i2.1705
}

\begin{abstract}
Styrofoam adalah sejenis limbah plastik yang sulit terurai,dan didaur ulang, sehingga limbah Styrofoam akan terus menggunung dan merusak lingkungan. Penelitian ini merupakan studi mengenai "Pengaruh Penggunaan Styrofoam terhadap Kinerja Perkerasan Aspal Porus". Pemanfaatan limbah untuk meningkatkan kinerja perkerasan jalan dan menyelamatkan lingkungan dengan mengurangi jumlah limbah terutama limbah Styrofoam. Penelitian ini bertujuan untuk menentukan kadar aspal optimum campuran asphalt porus yang menghasilkan kinerja perkerasan optimum dengan menggunakan metoda Australia Asphalt Pavement Association (AAPA, 2004) serta untuk mengetahui pengaruh subtitusi Styrofoam pada aspal terhadap kinerja perkerasan. Parameter untuk menentukan kadar aspal optimum yaitu; nilai Cantabro Loss (CL), Asphalt Flow Down (AFD) dan Void in Mix (VIM). Berdasarkan hasil penelitian diperoleh nilai KAO 5,65\% dengan nilai kinerja perkerasan optimum yaitu; stabilitas 555,75 kg, flow 5,46 mm, VIM 22,15\%, MQ 101,89 kg/mm, CL $16 \%$ dan AFD 0,29\%. Peningkatan subtitusi kadar Styrofoam pada KAO dan KAO $\pm 0,5 \%$ benda uji meningkatkan nilai stabilitas, vim, mq dan cl benda uji. Nilai flow dan nilai AFD campuran aspal porus menurun dengan meningkatnya subtitusi Styrofoam pada KAO dan KAO \pm 0,5\%.
\end{abstract}

Keywords: Aspal Porus, Styrofoam, Kinerja Perkerasan

\section{PENDAHULUAN}

Campuran Aspal membutuhkan perkuatan melalui bahan tambah yang dicampurkan kedalam aspal sebagai modifikasi dengan tujuan agar aspal pada temperatur rendah tidak rapuh/getas dengan demikian dapat mengurangi potensi terjadinya retak (cracking), disamping itu juga bertujuan untuk mencari sifat baru aspal dan meningkatkan nilai stabilitas serta kekuatannya. Campuran asphalt porus biasanya digunakan sebagai lapisan permukaan pada perkerasan jalan (Saleh, 2014). Campuran aspal porus merupakan jenis cempuran perkerasan yang bergradasi terbuka, dimana persentase agregat kasar besar, dan berpori sehingga dapat mengalirkan air permukaan, dengan demikian air tidak menggenangi bagian permukaan jalan. (Diana, 1995). Tabel 1 menampilkan tipe nilai tengah gradasi aspal porus.

Aspal porus memiliki stabilitas rendah, sehingga membutuhkan aspal dengan mutu yang baik yang berfungsi sebagai pengikat dalam campuran. Untuk itu penggunaan limbah Styrofoam yang dicampurkan kedalam bahan pengikat aspal untuk meningkatkan mutu aspal porus dilakukan pada penelitian ini.
Tabel 1. Tipe gradasi aspal porus

\begin{tabular}{|c|c|c|}
\hline \multirow{2}{*}{$\begin{array}{c}\text { Diameter Saringan } \\
(\mathbf{m m})\end{array}$} & \multicolumn{2}{|c|}{ Diameter Agregat Maksimum } \\
\cline { 2 - 3 } & $\mathbf{1 0} \mathbf{~ m m}$ & $\mathbf{1 4} \mathbf{~ m m}$ \\
\hline 19,0 & 100 & 100 \\
\hline 13,2 & 100 & $85-100$ \\
\hline 9,5 & $85-100$ & $45-70$ \\
\hline 4,75 & $20-45$ & $10-25$ \\
\hline 2,36 & $10-20$ & $7-15$ \\
\hline 1,18 & $6-14$ & $6-12$ \\
\hline 0,6 & $5-10$ & $5-10$ \\
\hline 0,3 & $4-8$ & $4-8$ \\
\hline 0,15 & $3-7$ & $3-7$ \\
\hline 0,075 & $2-5$ & $2-5$ \\
\hline Total & 100 & 100 \\
\hline Kadar Aspal & $5,0-6,5$ & $4,5-6,0$ \\
\hline
\end{tabular}

Sumber: AAPA, (2004)

Pemanfaatan limbah dari bahan polimer merupakan salah satu teknik modifikasi aspal seperti penggunaan limbah Styrofoam. Styrofoam adalah jenis plastik yang terbuat dari $90 \%-95 \%$ polystyrene dan 5\%-10\% gas seperti n-butana atau npentane. Styrofoam banyak digunakan dalam kehidupan salah satunya sebagai penyangga alat elektronik (Putri dan Syamsuwirman, 2016). 
Limbah Styrofoam merupakan sampah yang sulit terurai dan tidak dapat dengan mudah didaur ulang. Limbah Styrofoam akan tetap pada bentuknya, tidak berubah atau hilang sampai akhir hidup. Limbah Styrofoam akan terus menggunung dan jika dibuang ke sungai atau saluran air, akan menyumbat saluran air dan mengakibatkan banjir yang akan merusak lingkungan.

Penggunaan Styrofoam sebagai aditif adalah karena memiliki perilaku termoplastik, padat pada suhu ruangan, dan akan meleleh jika dipanaskan di atas $100^{\circ} \mathrm{C}$, selanjutna akan menjadi kaku lagi ketika didinginkan. Di sisi lain, Styrofoam menolak asam, basa, dan perilaku korosif lain. Satu dari fungsi Styrofoam adalah sebagai perekat bila dicampur dengan bensin. Maka penambahan Styrofoam ke dalam aspal diharapkan untuk meningkatkan adhesi antara agregat dan aspal. Sehingga itu akan meningkatkan kualitas campuran perkerasan yang memenuhi persyaratan, dengan demikian, limbah Styrofoam dibuang ke tempat pembuangan akhir (TPA) berkurang (Mashuri, 2010).

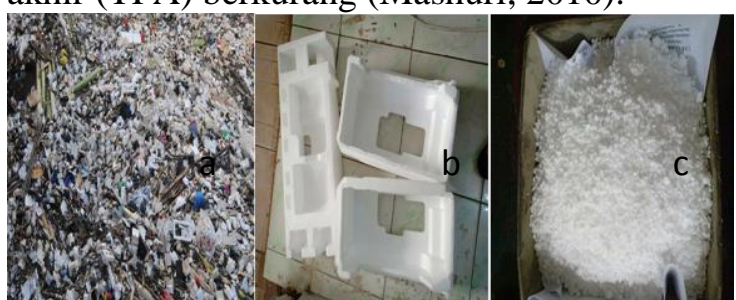

Gambar 1. (a) Limbah Styrofoam dan Plastik di Sungai Indonesia; (b) Styrofoam dari

Penyangga Alat Elektronik (c) Styrofoam Setelah Dihaluskan

Penelitian ini merupakan studi mengenai "Penggunaan Limbah Styrofoam Pada Perkerasan Aspal Porus". Pemanfaatan limbah untuk meningkatkan kinerja perkerasan jalan dan menyelamatkan lingkungan dengan mengurangi jumlah limbah terutama limbah Styrofoam

Tujuan penelitian ini adalah untuk menentukan kadar aspal optimum pada campuran perkerasan aspal porus yang menghasilkan nilai kinerja perkerasan optimum, serta melihat pengaruh subtitusi Styrofoam terhadap nilai kinerja perkerasan aspal porus.
Tabel 2. Spesifikasi Aspal Porus

\begin{tabular}{|c|c|c|}
\hline No & Kriteria Perencanaan & Nilai \\
\hline 1 & Uji cantabro loss $(\%)$ & Maks 20 \\
\hline 2 & Uji Asphalt flow down (\%) & Maks 0.3 \\
\hline 3 & Stabilitas Marshall $(\mathrm{kg})$ & Min 500 \\
\hline 4 & Kelelehan Plastis $(\mathrm{mm})$ & $2-6$ \\
\hline 5 & Kadar Rongga Udara $(\%)$ & $18-25$ \\
\hline 6 & Kekakuan Marshall $(\mathrm{kg} / \mathrm{mm})$ & Maks 400 \\
\hline
\end{tabular}

Sumber: AAPA (2004)

\section{METODE PENELITIAN}

Jenis campuran perkerasan yang diuji adalah campuran aspal porus, dimana campuran ini merupakan gradasi terbuka, dengan menggunakan nilai tengah agregat maksimum $14 \mathrm{~mm}$ berdasarkan spesifikasi dari AAPA (2004).

Subtitusi Styrofoam dilakukan ke dalam aspal penetrasi 60/70 dengan variasi subtitusi $0 \%, 10 \%, 15 \%$, dan $20 \%$ terhadap berat aspal dan Styrofoam yang dimanfaatkan adalah Styrofoam untuk pengamanan dan penyangga barang elektronik. Penentuan Kadar aspal optimum (KAO) menggunakan metode Australia dengan parameter nilai Cantabro Loss, Asphalt Flow Down dan Voids in Mix.

Jumlah benda uji yang dibuat sebanyak 153 buah dengan yang dibagi menjadi 2 kelompok antara lain kelompok pertama benda uji untuk penentuan KAO sebanyak 45 buah masing-masingnya digunakan untuk pengujian Marshall 15 buah, pengujian CL 15 buah dan pengujian AFD 15 buah, kelompok benda uji kedua berjumlah 108 buah yang digunakan untuk pengujian kinerja perkerasan campuran aspal porus dengan variasi persentase subtitusi Styrofoam terhadap kadar aspal.

Komposisi campuran untuk benda uji dibuat dengan perbandingan berat dan sesuai dengan komposisi campuran menurut nilai tengah gradasi aspal porus (AAPA, 2004). Kadar aspal yang digunakan berdasarkan AAPA (2004), untuk ukuran agregat maksimum $14 \mathrm{~mm}$ yaitu antara 4,5-6,5\% dari total berat campuran dengan variasi yang digunakan sebanyak 5 variasi kadar aspal dengan interval $0,5 \%$ yaitu $4,5 \%, 5 \%, 5,5 \%$, $6 \%$, dan $6,5 \%$ terhadap berat total campuran. 
Pemeriksaan sifat-sifat fisis aspal meliputi pemeriksaan penetrasi, berat jenis, titik lembek dan berat yang hilang dengan dan tanpa subtitusi Styrofoam. Pengujian sifat-sifat fisis agregat meliputi pemeriksaan berat jenis dan penyerapan agregat, Pemeriksaan abrasi dengan mesin Los Angeles dan kelekatan agregat terhadap aspal.

\section{HASIL DAN PEMBAHASAN}

Hasil pemeriksaan aspal dengan dan tanpa subtitusi Styrofoam dapat dilihat pada table 1 dan hasil pemeriksaan agregat pada table 2 berikut.

\section{Tabel 3. Pemeriksaan Aspal}

\begin{tabular}{|c|c|c|c|c|c|c|}
\hline Pemeriksaan & $\begin{array}{c}\text { Aspal } \\
+0 \% \\
\text { Styrof } \\
\text { oam }\end{array}$ & $\begin{array}{c}\text { Aspal } \\
+10 \% \\
\text { Styrof } \\
\text { oam }\end{array}$ & $\begin{array}{c}\text { Aspal } \\
+15 \% \\
\text { Styrof } \\
\text { oam }\end{array}$ & $\begin{array}{c}\text { Aspal } \\
+20 \% \\
\text { Styrof } \\
\text { oam }\end{array}$ & Spesifikasi & Standart \\
\hline $\begin{array}{c}\text { Kehilangan } \\
\text { Berat }\end{array}$ & 0.477 & 0.35 & 0.23 & 0.117 & $\leq 0.8$ & $\begin{array}{l}\text { SNI 06-6442- } \\
2000\end{array}$ \\
\hline Titik Lembek & 49.5 & 52.5 & 54.3 & 55.5 & $\geq 48$ & SNI-2434:2011 \\
\hline Berat jenis & 1,03 & 1,029 & 1,027 & 1,02 & $\geq 1.0$ & SNI-2441:2011 \\
\hline $\begin{array}{c}\text { Kelekatan } \\
\text { terhadap batuan } \\
(\%)\end{array}$ & $>95$ & $>95$ & $>95$ & $>95$ & $>90 \%$ & PA- $0312-76$ \\
\hline $\begin{array}{c}\text { Penetrasi aspal } \\
\text { Tanpa } \\
\text { kehilangan berat }\end{array}$ & 68,8 & 65,4 & 63 & 61.5 & $60-70$ & SNI 2456:2011 \\
\hline $\begin{array}{c}\text { Dengan } \\
\text { kehilangan berat }\end{array}$ & 63,4 & 60,2 & 57,5 & 55,4 & $\geq 54$ & SNI 2456:2011 \\
\hline
\end{tabular}

Tabel 4. Pemeriksaan Agregat

\begin{tabular}{|c|c|c|c|c|}
\hline & Pemeriksaan agregat & Standart Pengujian & Persyaratan & Hasil \\
\hline \multirow[t]{5}{*}{1} & $\begin{array}{l}\text { Berat jenis dan penyerapan agregat } \\
\text { kasar }\end{array}$ & & & \\
\hline & - Berat jenis (bulk) & \multirow{4}{*}{ SNI 1969-2008 } & $\operatorname{Min} 2.5$ & 2.62 \\
\hline & - Berat jenis SSD & & - & 2.65 \\
\hline & - Berat jenis semu & & - & 2.63 \\
\hline & - Penyerapan agregat (\%) & & Mak $3 \%$ & 1.134 \\
\hline \multirow[t]{5}{*}{2} & $\begin{array}{l}\text { Berat jenis dan penyerapan agregat } \\
\text { halus }\end{array}$ & & & \\
\hline & - Berat jenis (bulk) & \multirow{4}{*}{ SNI 1970-2008 } & $\operatorname{Min} 2.5$ & 2.62 \\
\hline & - Berat jenis SSD & & - & 2.69 \\
\hline & - Berat jenis semu & & - & 2.83 \\
\hline & - Penyerapan agregat $(\%)$ & & Mak 5\% & 2.82 \\
\hline \multirow[t]{4}{*}{3} & Berat isi & & & \\
\hline & - Isi lepas & \multirow{3}{*}{ ASTM C-29-71 } & - & 1453,18 \\
\hline & - Cara penusukan & & - & 1531,96 \\
\hline & - Cara penggoyangan & & - & 1627,68 \\
\hline 4 & Kelekatan agregat terhadap aspal (\%) & SNI 2439-2011 & Min $95 \%$ & 95 \\
\hline 5 & Keausan agregat dengan mesin $\mathrm{LA}(\%)$ & SNI 2417-2008 & Maks $40 \%$ & 25,058 \\
\hline
\end{tabular}

Subtitusi Styrofoam menyebabkan berat jenis turun $0.1-0.97 \%$, penetrasi tanpa kehilangan berat turun $4-10,61 \%$, penetrasi dengan kehilangan berat turun $5-12.62 \%$ dari nilai tanpa adanya subtitusi styrofoam. Kehilangan berat semakin kecil dengan adanya subtitusi Styrofoam yaitu $26-75.5 \%$ dari nilai kehilangan berat $0 \%$ styrofoam, sedangkan titik lembek meningkat $6-12.12 \%$ dari nilai titik lembek tanpa subtitusi styrofoam.

Menurunnya nilai penetrasi pada peningkatan kadar Styrofoam mengindikasikan bahwa subtitusi Styrofoam kedalam aspal berkaitan dengan tingkat kekerasan asphalt. Asphalt menjadi lebih keras dengan adanya penggantian sebagian aspal dengan Styrofoam hal ini ditunjukkan dengan terjadi peningkatan titik lembek.

Hasil pemeriksaan aspal dan agregat telah memenuhi persayaratan yang ditetapkan dalam spesifikasi umum Bina Marga tahun 2018.

\section{Penentuan Kadar Asphalt Optimum}

Penentuan nilai KAO dengan menggunakan metode Australia, yang hanya mensyaratkan tiga parameter yaitu VIM, CL dan AFD seperti yang terlihat pada gambar 2 nilai $\mathrm{KAO}$ diperoleh sebesar 5,65\%.

Tabel 5. Hasil pengujian Marshall, CL dan

AFD

\begin{tabular}{|c|c|c|c|c|c|c|c|}
\hline \multirow[b]{2}{*}{ NO } & \multirow{2}{*}{$\begin{array}{l}\text { KARAKTERISTIK } \\
\text { CAMPURAN }\end{array}$} & \multicolumn{5}{|c|}{ KADAR ASPAL (\%) } & \multirow{2}{*}{$\begin{array}{c}\text { SPESIFIKASI } \\
\text { AAPA }\end{array}$} \\
\hline & & 4.5 & 5.0 & 5,5 & 6.0 & 6.5 & \\
\hline 1 & Stabilitas (kg) & 539.96 & 573.64 & 581.36 & 497.65 & 440.99 & Min 500 \\
\hline 2 & Flow (mm) & 3.87 & 4.88 & 5.33 & 5.53 & 5.40 & $2-6$ \\
\hline 3 & VIM (\%) & 33.15 & 31.82 & 21.04 & 18.67 & 16.87 & $18-25$ \\
\hline 4 & MQ (kg/mm) & 139.9 & 117.51 & 109.21 & 89.98 & 81.72 & Mak 400 \\
\hline 5 & Cantabro Loss (\%) & 23 & 18 & 17 & 16 & 13 & Maks 20 \\
\hline 6 & $\begin{array}{l}\text { Asphalt Floww } \\
\text { Down (\%) }\end{array}$ & 0.151 & 0.240 & 0.257 & 0.343 & 0.477 & Maks 0.3 \\
\hline
\end{tabular}

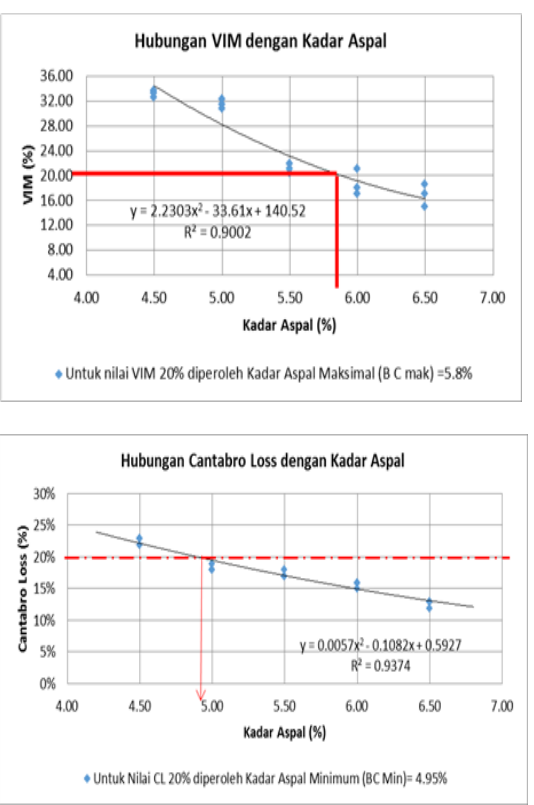




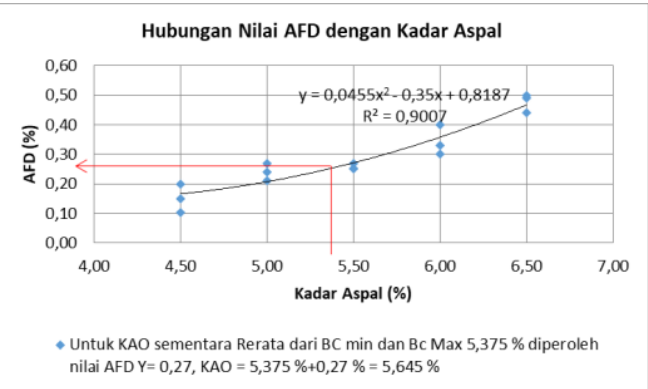

Gambar 2. Penentuan KAO Metode AAPA

Pengaruh Subtitusi Styrofoam terhadap Kinerja Perkerasan Aspal Porus

Setelah KAO diperoleh melalui metode AAPA, selanjutnya dilakukan pengujian, pada $\mathrm{KAO}$ dan $\mathrm{KAO} \pm 0,5$ dengan variasi subtitusi Styrofoam 0\%, 10\%, 15\% dan 20. Pengaruh Subtitusi Styrofoam terhadap nilai kinerja perkerasan aspal porus pada $\mathrm{KAO}$ dan $\mathrm{KAO} \pm$ 0.5, dapat dilihat pada Gambar 3 sampai dengan Gambar 3.

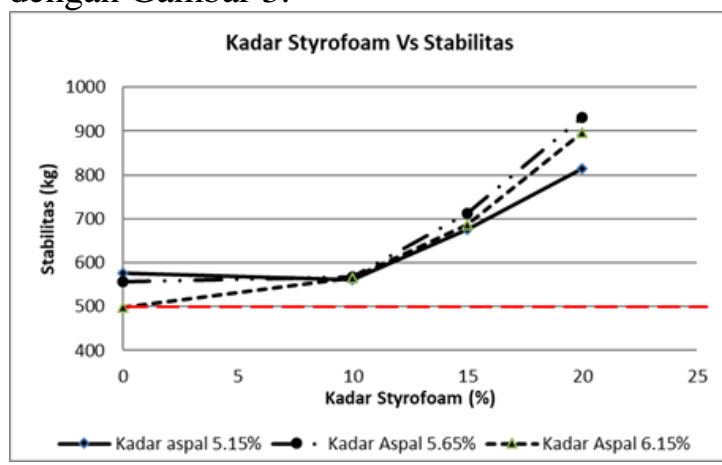

Gambar 3. Kadar Styrofoam vs. Stabilitas

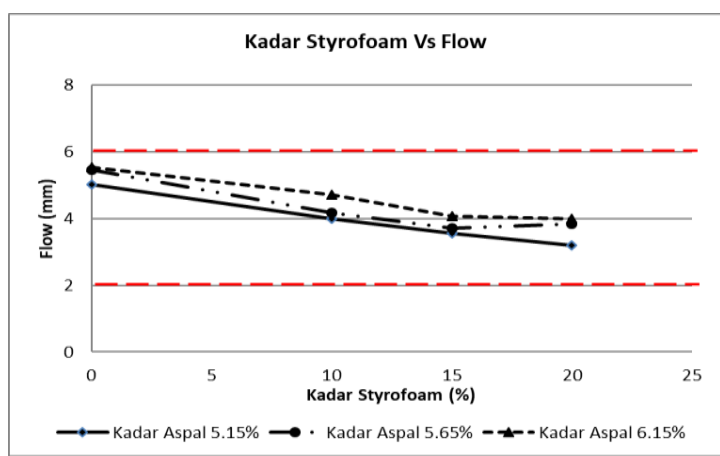

Gambar 4. Kadar Styrofoam vs.Flow

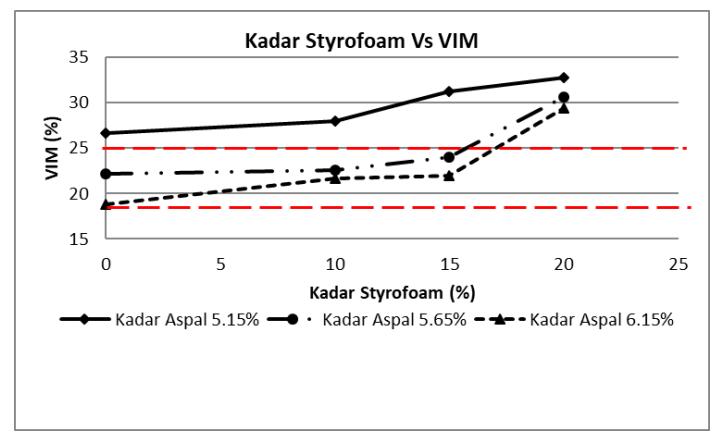

Gambar 5. Kadar Styrofoam vs.VIM

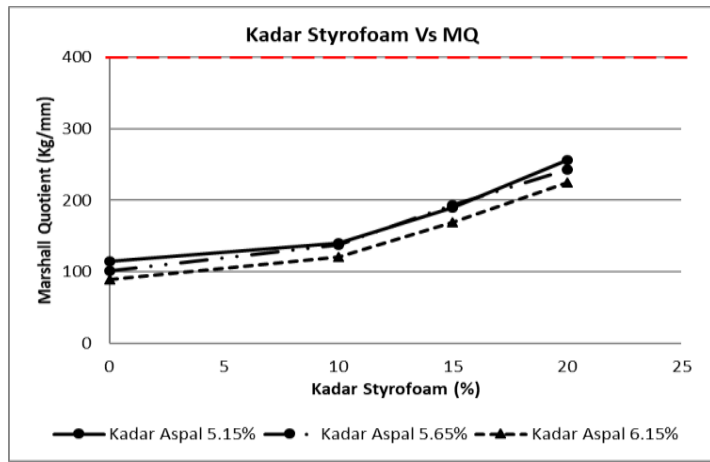

Gambar 6. Kadar Styrofoam vs. MQ

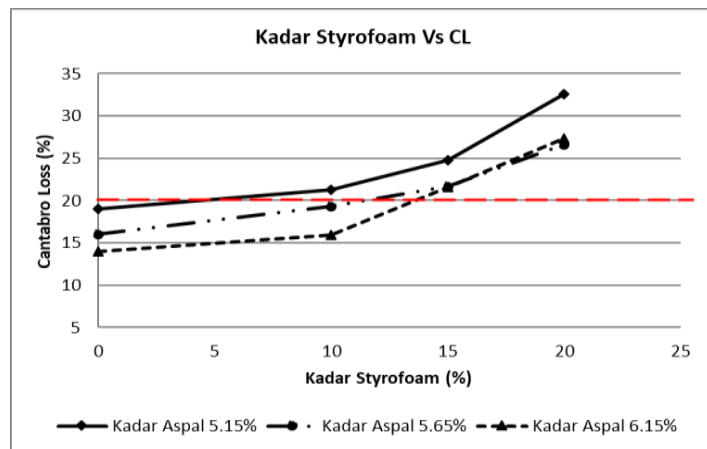

Gambar 7. Kadar Styrofoam vs. CL

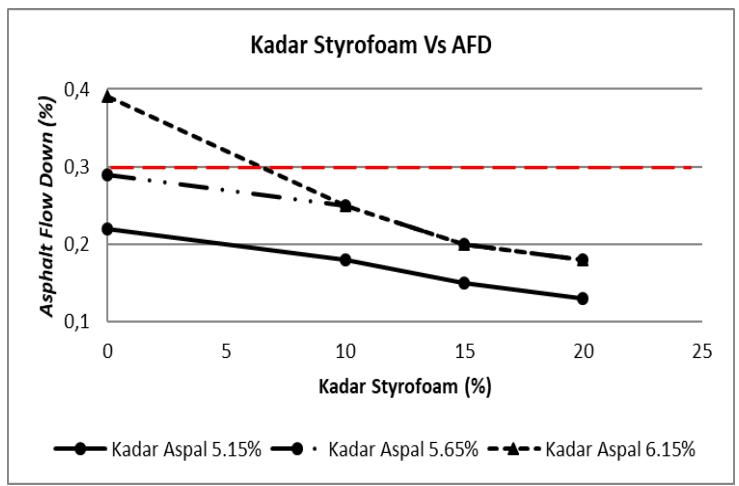

Gambar 8. Kadar Styrofoam vs. AFD 


\section{Stabilitas}

Dari gambar 3 terlihat peningkatan subtitusi kadar Styrofoam pada $\mathrm{KAO} \pm 0,5 \%$ meningkatkan nilai stabilitas campuran, dimana nilai stabilitas maksimum diperoleh pada kadar subtitusi Styrofoam 20\% dengan kadar aspal $5.65 \%$, nilai stabilitas $931,59 \mathrm{~kg}$.

\section{Flow}

Semakin tinggi penambahan kadar styrofoam, nilai flow campuran aspal porus juga semakin turun, hal ini terlihat pada gambar 3, namun penambahan 0\%, 10\%, 15\% dan $20 \%$ Styrofoam pada $\mathrm{KAO} \pm 0.5 \%$ sample masih memenuhi syarat yang ditetapkan dalam AAPA (2004) yaitu 2-6 mm..

\section{Void in Mix (VIM)}

Void In Mix (VIM), memperlihatkan persentase rongga udara didalam campuran setelah pemadatan. Gambar 5 memperlihatkan penambahan Styrofoam pada $\mathrm{KAO} \pm 0.5 \%$ sample meningkatkan persentase rongga udara dalam campuran. Penambahan 0\%, 10\% dan $15 \%$ stryrofoam pada $\mathrm{KAO} \pm 0.5 \%$ sample masih memenuhi syarat yang ditetapkan AAPA (2004), namun pada penambahan $20 \%$ Styrofoam, nilai VIM terlalu tinggi dan melewati batas yang telah ditetapkan yaitu 18 $25 \%$.

\section{Marshall Quotient}

AAPA mensyaratkan batas nilai MQ untuk campuran aspal porus maksimal 400 $\mathrm{kg} / \mathrm{mm}$, penambahan kadar subtitusi Styrofoam pada $\mathrm{KAO} \pm 0.5 \%$ sample meningkatkan nilai kekakuan dari sample, hal ini terlihat pada gambar 5, dimana peningkatan kadar subtitusi Styrofoam meningkatkan nilai MQ, ini mengidentifikasi campuran aspal semakin kaku. Subtitusi Styrofoam 0\%, 10\%, $15 \%$ dan $20 \%$ pada $\mathrm{KAO} \pm 0.5 \%$ sample masih memenuhi syarat yang ditetapkan AAPA (2004), maksimal $400 \mathrm{~kg} / \mathrm{mm}$.

\section{Cantabro Loss}

Pada gambar 7 terlihat penambahan kadar subtitusi Styrofoam pada $\mathrm{KAO} \pm 0.5 \%$ meningkatkan nilai Cantabro Loss dari sample. AAPA (2004) mensyaratkan batas maksimum untuk nilai CL pada perkerasan campuran aspal porus sebesar $20 \%$. Subtitusi Styrofoam $0 \%$ dan $10 \%$ pada $\mathrm{KAO} \pm 0.5 \%$ masih memenuhi syarat, namun untuk penambahan kadar subtitusi Styrofoam sebesar $15 \%$ dan $20 \%$, nilai CL yang diperoleh secara berurut sebesar 21,68 dan 26,65\%, nilai ini melampau batas maksimum yang disyaratkan.

\section{Asphalt Flow Down}

Penambahan subtitusi Styrofoam 0\%, 10\%, $15 \%$ dan $20 \%$, pada $\mathrm{KAO} \pm 0.5 \%$ sample dapat menurunkan nilai Asphalt Flow Down (AFD), hal ini terlihat pada gambar 8, dimana nilai AFD terus menurun seiring dengan bertambahnya kadar Styrofoam yang disubtitusikan kedalam $\mathrm{KAO} \pm 0.5 \%$. Batas maksimal nilai aliran aspal berdasarkan AAPA (2004) yaitu $0,3 \%$. Persentase aspal yang melekat pada campuran akan makin banyak, apabila nilai aliran asphalt rendah.

\section{PENUTUP}

\section{Simpulan}

Hasil penelitian memperoleh nilai kadar aspal optimum dengan metode AAPA sebesar $5.65 \%$, dengan nilai kinerja perkerasan optimum yaitu stabilitas $555,76 \mathrm{~kg}$, Flow 5,46 mm, VIM 22,15\%, MQ 101,89 kg/mm, CL $16 \%$ dan AFD 0,29 \%. Peningkatan subtitusi kadar Styrofoam pada KAO dan KAO $\pm 0,5 \%$ benda uji meningkatkan nilai stabilitas, vim, mq dan cl benda uji, sebaliknya nilai flow dan nilai AFD campuran aspal porus menurun dengan meningkatnya subtitusi Styrofoam pada $\mathrm{KAO}$ dan $\mathrm{KAO} \pm 0,5 \%$. Nilai stabilitas maksimum dari benda uji diperoleh pada kadar subtitusi Styrofoam 20\% dengan kadar aspal $5.65 \%$, nilai stabilitas $931,59 \mathrm{~kg}$.

\section{Saran}

1. Perlu dilakukan penelitian sejenis dengan menggunakan bahan limbah lainnya yang tidak bisa terurai secara alamiah didalam tanah.

2. Penggunaan Styrofoam pada campuran perkerasan aspal porus dapat digunakan sebagai salah satu solusi dalam mengatasi besarnya jumlah limbah dilingkungan.

\section{DAFTAR PUSTAKA}

Australian Asphalt Pavement Association. (2004). National Asphalt Specifikation.

\begin{tabular}{llr}
\hline ISSN 2599-2081 & Fakultas Teknik UMSB & 171 \\
EISSN 2599-2090 & &
\end{tabular}


Bina Marga, Spesifikasi Umum (2018).

Direktorat Jendral Bina Marga. Departemen Pekerjaan Umum.

Cabrera, J.G \& Hamzah, M.O. (1996). Aggregate Grading Design For Porous Asphalt. London.

Diana. (1995). Aspal Porus. Fakultas Teknik, UNILA, Bandar Lampung.

Putri, E.E dan Syamsuwirman. (2016). Tinjauan Subtitusi Styrofoam Pada Aspal Pen.60/70 Terhadap Kinerja Campuran AsphaltConcrete - Wearing Course (ACWC). Jurnal Teknik Sipil. ISSN 20889321, Volume 6, No. 1.

Putri, E.E. (2018).The Effect Of Styrofoam Addition Into HRS-Base On Marshall Characteristics. Jurnal Teknik Sipil. ISSN 2088-5334, Volume 8, No. 5.

Saleh, S.M, Anggraini, R, Aquina, H. (2014). Karakteristik CampuranAspal Porus dengan SubstitusiStyrofoam pada Aspal Penetrasi60/70. Jurnal Teknik Sipil, ISSN0853-2982, Vol. 21 No. 3.

Sukirman, S. (2003), Beton Aspal Campuran Panas. Granit, Jakarta. 